\title{
Influence of Personality and Age on Attitude Towards Crime among Adolescents
}

\author{
Tobias C. Obi, ${ }^{*}$ Dr Barnabas E. Nwankwo, Solomon A. Agu, Dr. James U. \\ Aboh, Dr Ngozi Sydney-Agbor \\ Department of Psychology, Caritas University, Enugu \\ Department of Psychology, Enugu State University of Science and Technology \\ Department of Psychology, Imo State University Owerri
}

\begin{abstract}
This study investigated the influence of personality and age on attitude towards crime among adolescents. A total number of 176 participants comprising of 110 males (of different classes) and 66 females (of different classes) were selected from Command Secondary School Jos, Nigeria. They were between the ages of 12 and 20 (with the mean age of 15years). Two set of instruments were used, (Big Five Inventory (John et. al., 1991) and Attitude towards crime scale).Cross Sectional Survey research design was adopted while multiple linear Regression was applied as a statistical test to analyze the data. Two hypotheses were postulated and tested, one on personality and the other on age. The hypotheses on personality was further divided into five subhypotheses to explain the dimensions of the personality characteristics, the results were as follows; extroversion, $(\beta=.21, p<.01)$, agreeableness, $(\beta=.27, p<.05)$ conscientiousness, $(\beta=.27, p<.05)$, neuroticism $(\beta=-.01, p>.05)$, openness $(\beta=.19, p>.05)$. The first 3 personality characteristics were significant predictors of attitude towards crime while the other two were not. The second null hypothesis on age was not rejected ( $\beta=-$ $.13, p>.05)$ the implications of the findings were reviewed and suggestion for further studies were made.
\end{abstract}

Keywords: extroversion, agreeableness, conscientiousness, neuroticism, openness, age, attitude towards to crime

\section{Introduction}

Over the years, crime has caused loss of live and property as well as over whelming fear of insecurity. Crime is a challenge in human existence and has become a big problem in our society. Crime is universal, it is a common phenomenon in every society, but certain societies have recorded higher percentages of criminal activities than others. According to crime statistics by the Nigeria Police, crime has shown an upward trend in the past years in Nigeria. According to the Police Headquarters report in Lagos from October 1995 to October 2005, the risk has continued to increase yearly in arithmetic progression (Crime Statistics, Nigeria Police Headquarters Lagos, 2005). The increase in the rate of crime in this country has created a lot of problems to the Police Force and the Law Courts. Crime is a global problem but it varies in different societies or countries. For instance, in the Western world same sex marriage is a normal behaviour but in Nigeria, it is seen as a crime that is punishable by law. The House of Representatives had on May 30th 2013, passed the Anti-Same Sex Marriage Bill that makes same-sex unions in Nigeria a criminal offence punishable by a maximum sentence of 14 years in prison. The bill also criminalizes public displays of affection by same-gender partners. The bill also states that any person who registers, operates or participates in gay clubs, societies and organizations directly or indirectly, makes a public show of a same-sex amorous relationship commits an offence and shall be liable to a term of 10 years imprisonment. Crime has become so menacing in our society that it is now feared in some quarters that a great danger awaits the country in the nearest future. Crime is an act that violates the law of the society or serious offence against the law of the society for society for which there is a severe punishment by law (Eddiefloyd, 2006). Crime is any action or omission prohibited by law and punished by the state. Crime is a deviant behaviour that violates prevailing norms, which may be cultural, social, political, psychological and economic conditions. Crime is an act defined by law. It is an act or omission which renders the person doing the act or making the omission liable to punishment (Okonkwo, 1980). Durkheim (1951) defined crime within a social context. He saw crime as a social product, determined by social conditions, capable of being controlled only in social terms. Crime is therefore normal in all societies, and "a society exempt from crime would necessitate a standardization of moral concepts of all individuals, which is neither possible nor desirable (Durkhiem, 1951). Durkheim (1951) was of the opinion that crime is a normal phenomenon in the society, a natural and inevitable product of collective life and social evolution. He held that the collective conscience of a people defines what crime is. Durkheim (1951) believed that crime plays a definite role in social life. There are many types of crime. It is a well-known fact that when the word crime is mentioned, most people will normally 
focus on certain specific kinds of crime, usually conventional crimes of the street corner variety. But the truth is that crime and criminals are found everywhere, and there are many kinds of crimes and criminals. Several criteria have been employed by criminologists, (e.g Clinnard, 1973) to classify crime. Some of the many classes of crime include, violent crime, which involves the use of violence. Property crime, which involves the deprivation of property, they are crimes against property. Occupational crimes (e.g white-collar crimes), are crimes which take place in business and government circles. Organized crimes, this is the criminal activities of an organized network of people who work together in close structured association to make large profits through illegal means by using graft and corruption to protect their activities from criminal persecution. Person or Personal crime, involves harm or physical injury inflicted against a person. Victimless crime, are crimes without direct victim. Professional crimes, these are crimes by professional criminals who specialize in particular type of crime. It requires a long period of training, complex occupational skills, techniques and attitudes. Crime against Public Morality, these offend public standards of decency and right conduct. Crime against Lawful authority, these crimes violates the Federal, State, and Local Government authority laws on public order and environment. (Eddiefloyd, 2006).

Notwithstanding all the causes mentioned above, another potent factor that is often neglected on issue of crime and criminal behaviour is attitude. An individual predisposition towards crime, knowing attitude to be an individual expression on how much like or dislike he/she has over a thing, event, behaviour or object. It cannot be neglected in criminal behaviour. Attitudes are evaluation of ideas (such as the insanity defense), events (such as surprise parties), objects (such as abstract art) or people (such as sorority members). Fishbein (1993) sees attitude as a person's evaluation of an act or behaviour towards a specific act and is proposed to be a function of acts perceived consequences and of their value to that person. The underlining factor here is that attitude towards a particular object or event is influenced by the personal experience of the individual. In summary, an attitude is a learned predisposition to respond consistently in a position or negative way to some person, object or situation (Petty, Ostrom and Brock, 1981). Attitude has three basic components. These are

1. The cognitive component, which represents thoughts or beliefs.

2. The affective and emotional component which reflects feelings or emotional reacting and

3. The behaviour component which describes tendencies or predisposition towards certain actions based a particular attitude. (Allport, 1973).

Personality is that dynamic and organized set of characteristics possessed by a person who uniquely influences his or her cognitions, emotions, motivations, and behaviours in various situations. Personality is the unique and variable patterns of human behaviours, focusing on sensing, thinking, and feelings. The personality of the individual is the settled framework of references within which a person addresses the current situation and decides how to behave. Personality is a comprehensive, all embracing concept and the total pattern of characteristics ways of thinking, feeling, and behaving that constitute the individual's distinctive method of relating to the environment. Personality is a sum total psychological characteristic of a person that are common as well as unique. The integrated and dynamic organization of the physical mental, moral and social qualities of the individual, as that manifests itself to other people, in the give and take of social life (Ramalingam, 2006). Eysenck (1977) argued that personality influences behaviour. Conklin (1981), showed that the personality traits of offenders did differ from the general population, although, the differences were usually small. Zimbardo (1972) said that, there were some evidences that delinquents and criminals might be more emotionally disturbed than the general populations. Tenibiaje (1995) observed that the personality characteristics of juvenile delinquents and criminals were not similar, in terms of extroversion, neuroticism and psychoticism. Understanding why crime occurs requires an appreciation of the complexity of human behaviour. Behaviour is not determined by one factor, but rather influenced by a host of interrelated factors (Bandura, Reese \& Adams, 1982). For example, an individual's action to losing his or her job may vary according to factors such as age, coping skills, personality, level of social support, or financial status. Thus, both individual and structural level factors are essential to explaining current behaviour and to predicting future behaviour. Although Gottfredson and Hirshi (1990) are sociologists by training, they argued that people differ in an underlying criminal propensity, ie low self-control. According to self-control theory, the formation of the stable trait of self-control occurs via the parent-child socialization or the reciprocal bonding process from birth to age eight. Self-control theory shares strong conceptual link to personality theory (Farrington, 2002, Miller \& Lynam, 2001). However, other avenues of integration of personality with criminological theory could be useful. For example, Agnew's (1992) General Strain Theory, (GST) focuses on personal pressures arising from the environment that align with individual conditioning factors to press a person toward crime. Life strain by causing, influencing and interacting with negative emotions, aggressive personality traits, and criminogenic social learning are predicted to result in dysfunctional coping such as delinquent behaviours. Agnew (1992), predicted that crime is more likely when goal blockage is perceived as unjust and when the gap between goals and achievements is high in magnitude and the resulting anger and frustrations energize the individual for action and create a desire for revenge. Cohen and Felson, (1979), in their routine activity theory, which is classified as a criminal opportunity 
theory with concepts that emphasize victim risk, specifically noted that risk is created by proximity to crime and target suitability. Some researchers have recently asserted that, for some youth, victimization is a 'condition' rather than an event (Finkelher, Ormrad, Turner \& Heide, 1999). This youth do not experience only one or several separate incidents of victimizations, but endure repeated and multiple victimizations, as if being repeated victims comprise their own crime 'hot spot' (Menard \& Huizinga, 2001, Pease \& Laycock, 1996).

Moreover, it would also be suggested that age is another factor that influences attitude towards crime. Age can be the number of years that a person has lived or a thing has existed. It is a particular period of history. Erickson (1968), refer adolescent age, as period of "identity crisis". Adolescence is the period which starts from age 12/13 to the beginning of adulthood. An adolescent spend more time with peers, particularly with small groups of friends, than with parents, siblings or any other agent of socialization. (Berndt 1996; Larson \& Richards 1991). They tend to at this age have different groups that have developed dress codes, dialects, and behaviours that distinguish them from the other. Identifying with such groups can be harmful, particularly if evolving group norms encourage alcohol or drug use, sexual misconduct, or other kinds of antisocial or delinquent behaviours. Crime is a global problem. It has being a source of concern to every society. Crime is always seen as a major challenge to every society. A crime free society could be regarded as the best in the world. Owing to this, every society is using every instrument within its possession to ameliorate or eliminate crime to the barest minimum. In the same vein, researchers are not relenting in this effort. They work hard trying to contribute their quota towards this objective through research works. In as much as many researchers concentrated only the Political, Sociological and Economical factors paying little or no attention to psychological such as Personality, Attitude, Age etc. Therefore, this study deemed it necessary looking at the influence these factors could have on crime. Knowing fully well that an individual attitude towards a stimulus can be used to predict his actual behaviour towards such stimulus, the research believed that one of the best methods of preventing or controlling crime is to observe how those people perceive crime. We must not wait until an individual commits a crime before taking action. Through the person's attitude towards crime, one can predict what the individual will do when exposed to criminality. Therefore, the study will not only observe this predisposition but will also check whether variables such as age and personality will have an influence on the individual's attitude towards crime.

\section{Hypotheses}

The following hypotheses were postulated

The Big 5 Personality dimensions will not independently significantly predict attitude towards crime among adolescent.

Age will not significantly influence attitude towards crime among adolescent.

\section{Design/Statistics}

\section{Methods}

A cross sectional survey research design was adopted. This is because all the different personality and age groups were used at the same time. In addition, a multiple regression analysis was also adopted as a statistical tool. This is because the dimensions of the personalities were analyzed independently.

\section{Participants}

A total of 176 adolescents participants comprising 110 males and 66 females were used as sample for this study.The participants who were randomly selected using simple random sampling were sampled among Junior Secondary III students and above. They were within the age range of $12-20$ years with a mean age of $15 y e a r s$ and standard deviation of 2years. The participants were selected among the students of Command Secondary School Jos Plateau State. 99(56.25\%) of the participants were Christians while $77(43.75 \%)$ were muslims.

\section{Instruments}

The Big Five Inventory (BFI) by John, Donahue and Kentle (1991) was used in this study to measure the Big Five personality dimensions. The (BFI) is a questionnaire with 44 items. The 44 item inventory is one of the six psychological instruments which assess personality from a five-dimensional perspective. The 5 dimension or subscales or BFI are Extraversion, Agreeableness, conscientiousness, Neuroticism and openness. It has a response format in which the frequency scale ranges from 1 to 5 (1) Disagree strongly (2) Disagree a little (3) Neither agree nor disagree (4) Agree a little (5) Agree strongly. The scale is used for the study because it assesses personality. John et.al., (1991) provided the original psychometric properties for American samples, while Umeh. (2004) provided the properties for Nigerian samples. The norms reported here are the mean scores of samples drawn from a population of University students. However, a Crombach Alpha Co-efficient of .80 and a test re-test reliability of .85 on 3months interval were obtained by John et. Al., (1991). In addition a 
convergent validity coefficients of .75 and .85 were obtained with a Big Five instrument by Costa and McCrea (1992) and Goldberg (1992) respectively. Using Nigerian sample, Umeh (2004) obtained a divergent validity of .05 on Extraversion, .13 on Agreeableness, .11 on Conscientiousness .39 on Neuroticism, and .24 on Openness using maladjustment Scale by Kleinmuntz (1961).

The second instrument used in this study was Attitude towards Crime Scale. The Attitude towards Crime Scale was developed by the researcher. It is a 10 item instrument that was developed to assess the attitude of people towards crime. Sample items in the instrument are as follows; "Crime is a way of life", "Criminals should not be seen as evil dowers". The response options are strongly agree, disagree, undecided, agree, and strongly agree. The items were validated on a facial base (face validity). A total number of seven Lecturers from the department of psychology and sociology from Caritas University served as expert judges. They accepted/rejected the items on a facial case. Finally, only items accepted by the $2 / 3$ majority of the judges were used. In addition, the researcher obtained a crombach alpha reliability coefficient of 0.80 using 54 students from Command Day Secondary School Enugu.

\section{Procedure}

A total of two hundred copies of research questionnaire were randomly distributed to select the researcher must have secure approval from the school management. However, all the Junior Secondary Students III and above were assembled at the school hall. They were first divided into two categories of males and females. Inside each group, they were further sub-divided into two age groups i.e. junior adolescents (12years15years), senior adolescents (16years-20years). They were first administered the Big Five Inventory to differentiate their personality dimension. After which, simple random sampling technique making use of $5^{\text {th }}$ case was used to select participants from each cluster. Thus 120 copies of attitude toward crime questionnaire were administered on the sample. This exercise took the researcher a period of four weeks. Students meet on every Monday during break periods for this exercise. Finally, only one hundred and seventy six copies that were correctly filled and returned were used for data analysis and test of hypotheses.

\section{Results}

\section{Table 1}

Summary table of descriptive statistics on personality style, age and attitude towards crime.

\begin{tabular}{|c|c|c|c|}
\hline Variables & Mean & Standard Deviation & Number \\
\hline Extraversion & 29.97 & 3.92 & 176 \\
\hline Agreeableness & 30.67 & 1.97 & 176 \\
\hline Conscientiousness & 21.10 & 3.65 & 176 \\
\hline Neuroticism & 22.35 & 1.09 & 176 \\
\hline Openness & 42.00 & 3.01 & 176 \\
\hline Age & 15.49 & .99 & 176 \\
\hline Attitude towards crime & 40.25 & 4.84 & 176 \\
\hline
\end{tabular}

A total of 176 participants completed the questionnaire and the mean and standard deviation of the variables studies are summarized in table 1 .

Table 2

Model Summary table of personality style and age on attitude towards crime.

\begin{tabular}{|c|l|l|l|lr|}
\hline Model & $\mathrm{R}$ & $\begin{array}{l}\mathrm{R} \\
\text { Square }\end{array}$ & $\begin{array}{l}\text { Adjusted } \\
\text { R. Square }\end{array}$ & $\begin{array}{l}\text { Standard Error } \\
\text { Estimate }\end{array}$ & of \\
\hline 1 & .46 & .218 & .190 & 4.35749 & \\
\hline
\end{tabular}

Change Statistics

\begin{tabular}{|l|l|l|l|l|}
\hline R Square change & F Change & Df 1 & Df 2 & Significant \\
\hline .218 & 7.830 & 6 & 169 & .000 \\
\hline
\end{tabular}

The result of the regression analysis as presented in table 3 shows that the predictor variables accounted for $21.8 \%\left(\mathrm{R}^{2}\right.$ change) variance in attitude towards crime which is significant (F change $\left.(6,169)=7.83, \mathrm{p}<.001\right)$.

Table 3

Regression coefficient table of personality styles and age on attitude towards crime.

\begin{tabular}{|c|c|c|c|c|c|}
\hline & \multicolumn{2}{|c|}{ Unstandardized Coefficient } & \multirow{2}{*}{$\begin{array}{l}\text { Standardized } \\
\text { Coefficient } \\
\text { Beta }\end{array}$} & \multirow[b]{2}{*}{$\mathrm{t}$} & \multirow[b]{2}{*}{ Sig } \\
\hline & $\mathrm{B}$ & Std Error & & & \\
\hline Constant & 15.818 & 9.303 & & 1.700 & .091 \\
\hline Age & -.644 & .340 & -.132 & -1.890 & .060 \\
\hline Extraversion & .258 & .092 & .209 & 2.799 & .006 \\
\hline Agreeableness & .660 & .332 & .268 & 2.051 & .008 \\
\hline
\end{tabular}


Influence Of Personality And Age On Attitude Towards Crime Among Adolescents

\begin{tabular}{|l|l|l|l|l|l|}
\hline Conscientiousness & -.250 & .093 & -.118 & -2.702 & .008 \\
\hline Neuroticism & -.036 & .346 & -.008 & -.105 & .917 \\
\hline Openness & .298 & .226 & .185 & 1.319 & .189 \\
\hline
\end{tabular}

Dependent Variable: Attitude towards crime.

Table three (coefficient table) reveals that in the regression equation, extraversion is a significant predictor of attitude towards crime $(\beta=.21,<.01)$. Therefore, extraversion significantly predicted attitude towards crime. Also, agreeableness and conscientiousness are significant predictors of attitude towards crime $(\beta=.27, p<.05)$ and $(\beta=-.12 . p<.01)$ respectively. Both personality styles significantly influences attitude towards crime.

Neuroticism and openness are not significant predictors to attitude towards crime $(\beta=-.01, p>.05)$ and $(\beta=.19$, $\mathrm{p}>.05)$. Thus, both dimensions do not significant influence attitude towards crime among adolescents. Also age was not a significant predictor of attitude towards crime among adolescents. $(\beta=-.13, p>. \mathbf{0 5})$.

\section{Summary of the Findings}

Extraversion significantly predicted attitude towards crime among adolescents $(\beta=.21, \mathrm{p}<.01)$. Agreeableness significantly predicted attitude towards crime among adolescents $(\beta=.27, p<.01)$. Conscientiousness significantly predicted attitude towards crime among adolescents $(\beta=-.12, p<.01)$. Neuroticism is not a significant predictor of attitude towards crime among adolescents $(\beta=-.01$, ns). Openness is not a significant predictor of attitude towards crime among adolescents $(\beta=.19$, ns). Age is not a significant predictor of attitude towards crime among adolescents $(\beta=-.13, \mathrm{p}>.05)$.

\section{Discussion}

Considering the results, the first hypothesis on personality, which was divided into five sub hypotheses, they are extraversion, agreeableness, conscientiousness, neuroticism and openness, and were discussed as follows; The null hypotheses on Extraversion which stated that extraversion will not significantly predict attitude towards crime among adolescents was rejected. This results shows that adolescents who are extroverts have positive tendencies of manifesting strong attitude towards crime. This finding disagrees with the result obtained by Adegoke (1990) who reports that neuroticism and psychoticism are significant personality characteristics that influence attitude towards crime. However, the results are in collaboration with Tenibaje (1995) who observed that juvenile delinquents and criminals are individuals who manifest extroversion. The null hypotheses on agreeableness, was also rejected. Thus, the findings revealed that agreeable individuals are unconcerned with people, and therefore can be unfriendly and uncooperative. This personality characteristic predisposes an adolescent towards criminal tendencies and positive attitude towards crime. The null hypothesis on conscientiousness was also rejected. The result showed that conscientiousness significantly influences attitude towards crime among adolescents. Unconscientious individuals are characterized by carelessness and negligence and these qualities are possible precursors to criminal tendencies and could create a positive attitude towards crime. The null hypotheses on Neuroticism and Openness were not rejected. The study revealed that both personality characteristics did not significantly influence attitude towards crime among adolescents. The results disagree with the findings of Adegoke (1990), and Tenibaje (1995) who reported that individuals with both personality characteristics are prone to deliquence and criminal behaviours. Their reports showed that most criminals possess the characteristic of Neuroticism and Psychoticism. Also, Zimbardo (1972) findings disagree with the present findings because his results revealed a positive relationship between crime, neuroticism and psychoticism.

The hypotheses on the second independent variable which states that age will not significantly influence attitude towards crime among adolescents was not rejected. Thus, this shows that age does not significantly influence attitude towards crime among adolescents. This result corroborates the findings of Gottfredson and Hirschi (1990) who reported that age is not important in the explanation of crime. However, the present result disagrees with the findings of Statin and Magnusson (1989), Caspi, Henry, McGree, Moffits and Silva (1995), who reported that age is a significant factor in criminality. These researchers argued that an individual's age will significantly influence the person's attitude towards aggression, violence and crime. They believe that criminal behaviour is as the result of age related factor, Moreover, the present study has proved otherwise, showing that among adolescents, age does not significantly exert any influence on attitude towards crime.

There are several implications of the findings of the present study. Several deductions can be made that can benefit future researchers, parents and the society at large. The result revealed that extraversion significantly influences attitude towards crime among adolescents. Extraverts enjoy being with people, expecting friends and peers and they shows sign of full of energy and often experience positive emotions. The implications are that these adolescents who enjoy social gathering are more likely to mix up with friends who have criminal intentions and tendencies. An adolescent who exercises his/her youthful exuberance and energy, is most likely to become a deviants in the society and this can boost the individual's attitude towards crime. Extraverts tend to engage in physical emotional and social activities that will satisfy their curiosity. Agreeableness as a dimension 
of personality characteristics also significantly influenced attitude towards crime among adolescents this personality characteristics reflects individual differences with respect to cooperation and social harmony. Agreeable individuals value harmonious relationship with others, therefore, they are considered as being considerate, friendly, generous, helpful and willing to compromise their interest with others. To this effect, adolescents who show sign of disagreeableness are always unconcerned with other people, lack cooperation and social harmony. Therefore, such adolescents could be violent, instructive and uncaring. Such individuals could easily commit crime because they are mostly unfriendly. They are most likely to have positive attitude towards crime because they are likely perpetrators of such crimes. These adolescents that manifest the disagreeable personality are mostly delinquents and vulnerable to detrimental influences thus, families should monitor their children to avoid dysfunctional behaviours. People tend to enjoy what they are good at; adolescents who possess the disagreeable personality are prone to crime and violence and therefore will mostly elicit a positive attitude towards crime.

With regards to conscientiousness, individuals who manifest this personality characteristic know how to control, regulate and direct their impulses. The impulses of a conscientious adolescent is not inherently bad because conscientious individuals are likely to avoid trouble and achieve high levels of success through purposeful planning and persistence. Therefore, the unconscientious adolescents are characterized by negligence, carelessness, laziness and lack of ambition as well as failure to stay within the times, and these are the class of adolescents that are most likely to commit crime because of their care free attitude towards life. Such adolescents have the tendency of easily manifesting violent and destructive behaviours, thus will mostly have a strong positive attitude towards crime. This type of adolescents could also become delinquents, bullies, truants and above all dysfunctional in social communication. Parents and society with children of personality characteristics will mostly require reformation center where they could be rehabilitated towards becoming law abiding citizens and also several sources of deterrence should be encouraged so as to check their positive attitude towards crime. Both Neuroticism and Openness were not identified as significant factors or personality characteristics that can influence an adolescent's attitude towards crime. Though Neurotic individuals may likely have negative feelings such as anxiety or depression, such behaviours not necessarily influence their attitude towards crime. Besides, the open individuals are intellectually curious, appreciative and sensitive and have little time to put up deviant behaviour, thus having little room for creating positive attitude towards crime. The study has also showed that age is not a significant factor in attitude towards crime among adolescents. The implication is that irrespective of the age of an adolescent, the individual may be influenced by peer group, family, and probably the social class of the parents. A young or old adolescent may or may not be disposed to criminal activity and therefore may or may not have strong attitude towards crime.

\section{Conclusion}

This study investigated the influence of personality and age on attitude towards crime among adolescents. From the results obtained in the study, some personalities were identified as significant factors in attitude towards crime among adolescents. The personality characteristics that significantly influenced the attitude of adolescents towards crime are Extraversion, Agreeableness and Conscientiousness while Neuroticism and Openness were not identified as characteristics that will influence attitude towards crime among adolescents. Also, the study found that age is not a significant factor in attitude towards crime among adolescents. Really, it can be clearly stated that the importance of personality cannot be over emphasized. Personality still remains a significant factor to consider while studying human behaviour. Whether the behaviour is normal or abnormal with regards to the cultural setting of the individual, the study of personality characteristics will help to deduce the reason(s) for such behaviour. Also, it is a significant factor in determining our belief, perception, opinions and attitudes towards an event, a behaviour or a thing. Parents must learn to study and control those personality characteristics that may predispose their children toward deviant behaviour, because a positive attitude towards a behaviour may likely lead to such a behaviour. Finally, individual and situational factors that will help improve the desired personality characteristics should be encouraged.

\section{References}

[1]. Adegoke, A.A. (1990). A comparative study of prisoners and non- prisoners on three personality dimensions. Journal of Research Counsel Psychology., 2(1): 46-51.

[2]. Agnew, R.(1992). Foundation for a general strain theory of crime and deliquency. Criminology, $30,47-87$.

[3]. Allport, G. (1973). Attitudes. In C.A Murchinson (ed), a handbook of social psychology mass: Clerk University Press.

[4]. Bandura, A., Reese, L., \& Adams, N. E. (1982).Microanalysis of action and fear arousal as a function of differential levels of perceived self-efficacy. Journal of Personality and Social Psychology, 43, 5-21

[5]. Berndt, T.J. (1996). Exploring the effects of friendship quality on social development. In W.M. Bukowski, A.F. Newcomb, \& W.W. Hartup (Eds.), The company they keep: Friendship in childhood and adolescence (pp. 346-365). Cambridge, England: Cambridge University Press.

[6]. Caspi, A., Moffits, T.E., \& Silva, P. A.(1995).Temperamental qualities at age three Predicts personality traits in young adulthood; Longitudinal evidence from a Birth control. Child Development, 66,484-498. 
[7]. Clinnard, M.B., \& Quinney, R. (eds). (1986). Criminal Behaviour Systems: a typology (2 ${ }^{\text {nd }}$ edition.), New York: Anderson Publishing.

[8]. Cohen, L. E., \& Felson, M. (1979).Social change and crime rate trends: A routine activity approach. American Sociological Review, 44, 588-608.

[9]. Conklin, J.E. (1981). Criminology. 2nd Edition.,Cellier Macmillan, London.

[10]. Costa, P. T., \& McCrae, R. R. (1992). NEO PI-R. The Revised NEO Personality Inventory. Odessa FL: Psychology Assessment Resources.

[11]. Durkheim, E. (1951). Suicide Translated by J.A. Spaulding and George Simpson, New York: The Free Press.

[12]. Eddiefloyd, M. I. (2006). Criminology: A Basic Introduction ( $1^{\text {st }}$ edition). Jock-Ken publishers.

[13]. Erikson, E.H. (1968). Identity: Youth and Crisis. New York: Norton.

[14]. Eysenck, H.J. (1977). Crime and Personality. $3^{\text {rd }}$ Edition., Routledge and Kagen Paul, London.

[15]. Farrington, D. (2002). Explaining and Preventing Crime: The Globalization of Knowledge. Criminology 38: 1-24

[16]. Fishbein, M. (1993). Attitudes and Opinions, Review of Psychology 23:487-544.

[17]. Finkelhor, D., Ormrod, R., Turner, H. A., \& Hamby, S. L. (2005).The victimization ofchildren and youth: A comprehensive, national survey. Child Maltreatment, 10, 2-25.

[18]. Freud, S. (1923b). translated by Joan Riviere. (1927). 'The Ego \& the Id' (Hogarth Press/Institute of Psycho-Analysis, London).

[19]. Freud, S. (1933). 'New Introductory Lectures on Psychoanalysis' (Hogarth Press, London).

[20]. Freud, S. (1940). translated by James Strachey, (1949). 'An Outline of Psycho-Analysis' (Hogarth Press/Institute of PsychoAnalysis, London).

[21]. Gottfredson, M. R., \& Hirschi, T. (1990). A general theory of crime. Stanford, CA: Stanford University Press.

[22]. John, O. P., Donahue, E. M., \& Kentle, R. L. (1991). The Big Five Inventory--Versions 4a and 54. Berkeley, CA: University of California, Berkeley, Institute of Personality and Social Research

[23]. Larson, R. W., \& Richards, M. H. (1994).Family emotions: Do young adolescents and their parents experience the same states? Journal of Research on Adolescence, 4(4), 567-583.

[24]. Menard, S., \& Huizinga, D. (2001). Repeat victimization in a high-risk neighborhood sample of adolescents. Youth and Society, 32, $447-472$.

[25]. Miller, J. D., \& Lynam, D. (2001).Structural models of personality and their relation to antisocial behavior: A meta-analytic review. Criminology, 39, 765-798.

[26]. Nigerian Police Force. (2005).The Crime Figure Statistics. Nigeria Police Headquarter.

[27]. Okonkwo, C.O. (1980). Criminal Law in Nigeria ( $2^{\text {nd }}$ edition). Ibadan: Spectrum Books Limited.

[28]. Petty, R. E., Ostrom, T. M., \& Brock, T. C. (Eds.). (1981). Cognitive responses in persuasion. Hillsdale, NJ: Erlbaum.

[29]. Pease, K., \& Laycock, G. (1996).Revictimization: Reducing the heat on hot victims (NCJ Publication No.162951). Washington, DC: National Institute of Justice.

[30]. Ramalingam, P. (2006). Dictionary of Psychology. New Delhi. Academic (India) Publishers.

[31]. Stattin, H., \& Magnusson, D. (1989). The role of early aggressive behavior in the frequency, seriousness and types of later crime. Journal of Consult Clinical Psychology. 57:710-718.

[32]. Tenibiaje, D.J. (1995). Personality characteristic of juvenile delinquents and adult criminals in Ondo- state: A comparative study. Unpublished M.Ed. Thesis, Guidance and Counselling Department, University of Ilorin, Ilorin and Applied Psychology, 2(1).

[33]. Zimbardo, P.G. (1972). The pathology of imprisonment. Society, 9(6), 4-8. 